(Australia) OC registries. Patients on first-line maintenance with PARPis were excluded. Treatment characteristics including the use of neoadjuvant therapy, outcomes of cytoreductive surgery and the use of bevacizumab as maintenance were summarised with descriptive statistics. Duration of treatment, time to real world progression and any other time-to-event outcomes (e.g. overall survival, platinum based chemotherapy-free interval and time to first subsequent treatment and surgery) will be analysed using Kaplan Meier methodology.

Results Table 1 describes the demographic characteristics and treatment patterns of the study population. Overall, patients received a median of 6 cycles of primary platinum chemotherapy; complete or partial remission was the most common outcome. For patients with data on progression, the median time to first progression in months (two sided 95\% confidence interval) was 16.2 (14.6-18.1), $17.9(16.2-19.3)$ and 17.2 (14.7 19.7) in Australian, South Korean and Taiwanese patients, respectively. From the currently available dataset of patients with high grade serous type investigated for germline BRCA1/2 mutations: 30/169, 17.8\% (Australia), 80/354, $22.6 \%$ (South Korea) and 7/21, 33.3\% (Taiwan) of patients tested positive for germline BRCA1/2 mutations.

Abstract 257 Table 1 Demographic characteristics and treatment patterns in epithelial ovarian cancer

\begin{tabular}{lccc}
\hline Parameters & $\begin{array}{c}\text { Australia } \\
(\mathbf{N}=\mathbf{2 2 3})\end{array}$ & $\begin{array}{c}\text { South Korea } \\
(\mathbf{N}=\mathbf{5 1 3})\end{array}$ & $\begin{array}{c}\text { Taiwan } \\
(\mathbf{N = 1 2 0})\end{array}$ \\
\hline Median age, years & 65.2 & 56.0 & 59.5 \\
$\begin{array}{l}\text { Median weight, kgs } \\
\text { High-grade serous tumour, \% }\end{array}$ & 70.0 & 55.6 & 56.0 \\
$\begin{array}{l}\text { Interval debulking } \\
\text { surgery/neo-adjuvant chemotherapy, } \\
\text { \% }\end{array}$ & 82.5 & 84.6 & $100^{*}$ \\
$\begin{array}{l}\text { Platinum chemotherapy, \% } \\
\text { Bevacizumab+chemotherapy, } \mathrm{n}(\%)\end{array}$ & 56.5 & 24.0 & 9.1 \\
$\begin{array}{l}\text { Maintenance-bevacizumab, } \mathrm{n}(\%) \\
\text { Maintenance-others, } \mathrm{n}(\%)\end{array}$ & $59(29.6)$ & $84(16.4)$ & $23(19.2)$ \\
\hline *Taiwan only recruited women with high-grade serous ovarian cancer & $12(10.0)$ \\
\end{tabular}

Conclusion Although there were differences in demographics and treatment patterns, advanced-stage EOC had poor prognosis and relatively short progression-free intervals across AsiaPacific countries with well developed healthcare systems, highlighting the need to develop novel approaches to improve patient outcomes. Variation in the germline BRCA1/2 mutation rates across three datasets is probably due to differences in the composition of the contributing registries (clinic or cohort-based).

Disclosures Anna DeFazio has received a research grant from AstraZeneca.

David Bowtell has received research grants from AstraZeneca, BeiGene and Genentech Roche. David Bowtell is also a consultant for Exo Therapeutics.

Sian Fereday has received a research grant from AstraZeneca.

Nadia Traficante has received a research grant from AstraZeneca

Byoung-Gie Kim has received a research grant from AstraZeneca, Cellid and Eutilex.

Soo Young Jeong, Hung-Hsueh Chou, Chih-Long Chang, Heng-Chen Hsu and Wen-Fang Cheng have no conflict of interests to be declared

\section{SERUM MARKERS AND CYTOKINES IN PATIENTS WITH OVARIAN CANCER, ENDOMETRIOSIS OR OTHER BENIGN OVARIAN TUMOURS}

${ }^{1}$ Marek Nowak, ${ }^{2}$ Marcin Misiek, ${ }^{1}$ Łukasz Janas, ${ }^{1}$ Iwona Piwowarczyk, ${ }^{1}$ Malwina Soja, ${ }^{1}$ Martyna Masternak, ${ }^{3}$ Ewa Głowacka, ${ }^{4}$ Michał Kiełbik, ${ }^{4}$ Izabela Szulc-Kiełbik, ${ }^{4}$ Magdalena Klink. 'Department of Operative Gynecology and Gynecologic Oncology, Polish Mother's Memorial Hospital - Research Institute; ${ }^{2}$ Department of Gynaecology, Holy Cross Cancer Centre; '3aboratory Diagnostics Centre, Polish Mother's Memorial Hospital Research Institute; ${ }^{4}$ Institute of Medical Biology, Polish Academy of Sciences

\subsection{6/ijgc-2020-ESGO.109}

Introduction/Background The gold standard of serum tumour markers to detect ovarian cancer is cancer antigen 125 (CA125), human epididimis protein-4 (HE-4) and risk of ovarian malignancy algorithm (ROMA). However there is still need to improve its accuracy. Cytokines play a crucial role in tumour growth and progression according to proangiogenic and immunosuppressive acting. The aim of this study was to investigate the potential use of serum levels of selected cytokines in preoperative diagnosing of adnexal mass.

Methodology The study group consisted of 120 patients: 35 with epithelial ovarian cancer (EOC) and 85 with benign ovarian tumours (24 teratomas, 27 endometriotic and 34 other epithelial). We measured in sera obtained preoperatively the level of CA125, HE-4 and the panel of 6 cytokines: interleukin (IL) $1 \beta, 6,8,10,12$, tumour necrosis factor (TNF) using cytometric bead array (CBA) and one chemokine CXCL1/ GRO- $\alpha$ by ELISA method.

Results Serum levels of IL-6, IL-8, IL-10 and CXCL1/GRO- $\alpha$ were significantly higher in patients with ovarian cancer (2045 $\mathrm{pg} / \mathrm{ml} ; 208 ; 32 ; 356 \mathrm{pg} / \mathrm{ml}$, respectively) than in women with benign ovarian tumours $(17 \mathrm{pg} / \mathrm{ml} ; 29 ; 16 ; 127 \mathrm{pg} / \mathrm{ml}$, respectively). The similar pattern was present with standard ovarian cancer markers - CA125 (959 vs $43 \mathrm{U} / \mathrm{ml}$ ) and HE-4 (534 vs $51 \mathrm{pmol} / \mathrm{l})$. Other investigated cytokines had similar levels in all groups of patients. Analyzing the differences in the subgroups of women with benign ovarian tumours we didn't observe any significant except CA125 and IL-8; they were slightly elevated in cases of endometriotic ovarian cysts.

Conclusion Proinflammatory cytokines (IL-6, IL-8), immunosuppressive (IL-10) and CXCL1/GRO- $\alpha$ were elevated in sera of EOC patients what points on their role in cancer development. Moreover, they might be useful in preoperative differential diagnosis of ovarian tumors, as a supplemental markers especially as they were not elevated in cases of endometriosis. Disclosures All authors report no conflict of interest.

\section{REAL-WORLD-DATA ON PLATINUM OUTCOMES AFTER PARP INHIBITORS PROGRESSION IN HIGH GRADE SEROUS OVARIAN CANCER PATIENTS}

${ }^{1}$ Andrea Plaja Salarich, ${ }^{1}$ Iris Teruel García, ${ }^{2}$ Beatriz Pardo Burdalo, ${ }^{2}$ Marta Gil-Martin, ${ }^{2}$ Josep Maria Piulats Rodriguez, ${ }^{3}$ Claudia Fina Planas, ${ }^{3}$ María Pilar Barretina Ginesta, ${ }^{4}$ Andrea Gonzalez Valencia, ${ }^{4}$ Anna Esteve Gomez, ${ }^{1}$ Margarita Romeo Marin. ${ }^{1}$ Catalan Institute of Oncology (Ico)-Badalona, Germans Trias I Pujol University Hospital (Hugtip); BadalonaApplied Research Group in Oncology (B-Argo); Medical Oncology Department; ${ }^{2}$ Catalan Institute of Oncology (Ico)-Idibell, L'hospitalet; Medical Oncology Department; ${ }^{3}$ Catalan Institute of Oncology (Ico)-Girona, Girona Biomedical Research Institute (Idibgi); Medical Oncology Department; ${ }^{4}$ Catalan Institute of Oncology (Ico)-Badalona, Germans Trias I Pujol University Hospital (Hugtip); Badalona-Applied Research Group in Oncology (B-Argo); Statistics Department

10.1136/ijgc-2020-ESGO.110 